\title{
On the mechanism of action of gated molecular baskets: The synchronicity of the revolving motion of gates and in/out trafficking of guests
}

\author{
Keith Hermann, Stephen Rieth, Hashem A. Taha, Bao-Yu Wang, \\ Christopher M. Hadad and Jovica D. Badjić*
}

\section{Full Research Paper}

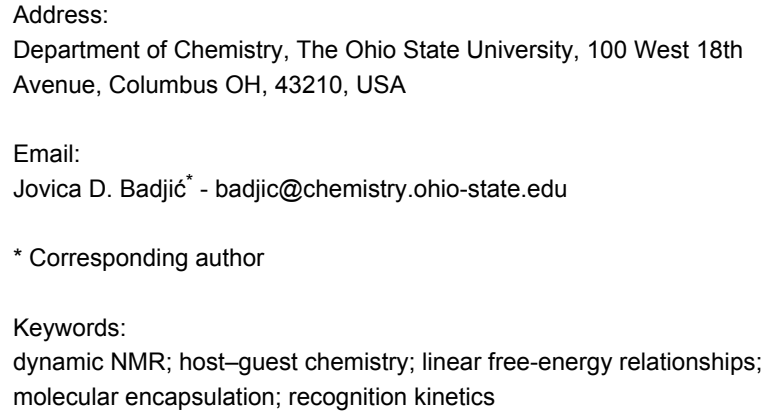

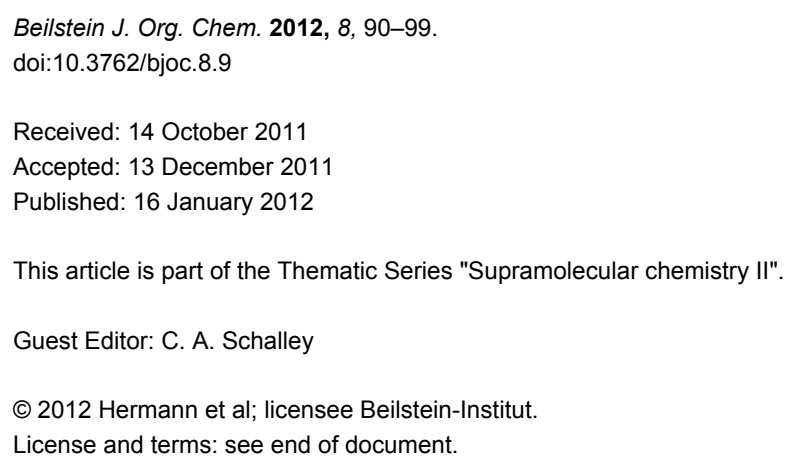

\begin{abstract}
We used dynamic ${ }^{1} \mathrm{H}$ NMR spectroscopic methods to examine the kinetics and thermodynamics of $\mathrm{CH}_{3} \mathrm{CCl}_{3}(2)$ entering and leaving the gated molecular basket $\mathbf{1}$. We found that the encapsulation is first-order in basket $\mathbf{1}$ and guest $\mathbf{2}$, while the decomplexation is zeroth-order in the guest. Importantly, the interchange mechanism in which a molecule of $\mathrm{CH}_{3} \mathrm{CCl}_{3}$ directly displaces the entrapped $\mathrm{CH}_{3} \mathrm{CCl}_{3}$ was not observed. Furthermore, the examination of the additivity of free energies characterizing the encapsulation process led to us to deduce that the revolving motion of the gates and in/out trafficking of guests is synchronized, yet still a function of the affinity of the guest for occupying the basket: Specifically, the greater the affinity of the guest for occupying the basket, the less effective the gates are in "sweeping" the guest as the gates undergo their revolving motion.
\end{abstract}

\section{Introduction}

Covalent and self-assembled molecules with a natural cavity, i.e., molecular capsules [1,2], employ several mechanisms to trap and release guests capable of residing in their inner space [3-5]. The so-called "slippage" scenario [6], in which a guest makes its way to and from the host by forcing the expansion of its aperture [7], appears frequently. The "gating" scenario [8], on the other hand, includes a conformational change in the host to create an opening that is large enough for a guest to "squeeze" its way in or out of the host. In the case of selfassembled hosts, however, the slippage, gating and possible partial or full disassembly of the capsule constitute mechanistic alternatives for the exchange of guests [4]. In the last decade, we [9-14] and others [7,8,15-18] have studied gated molecular encapsulation in artificial and natural systems [19]. 
In particular, we designed gated molecular baskets (Figure 1) and employed both experimental and theoretical methods to gain an understanding of their mechanism of action [4]. These dynamic hosts comprise a semirigid platform with three aromatic gates appended to its rim through $\mathrm{CH}_{2}$ "hinges" (Figure 1). The gates were set to interact by hydrogen bonding to control the opening and closing of the basket and thereby the rate by which a guest enters or departs the cavity of the basket [12-14]. Indeed, the action mechanism of the basket has been addressed [14], yet the exact role of the gates in the process of the in/out guest exchange necessitates additional scrutiny. In particular, a careful inspection of the additivity of free energies [21] pertaining to the constrictive $\Delta G^{\dagger}$ in/out and intrinsic $\Delta G^{\circ}$ binding energies of the guests [11] as well as the racemization of the basket $\Delta G^{\dagger}$ rac (i.e., opening and closing, see below in Figure 6) reveals a systematic disparity $\left(\Delta G^{\circ}+\Delta G^{\ddagger}{ }_{\text {rac }}+\right.$ $\Delta G_{\text {sterics }}^{\ddagger} \neq \Delta G^{\ddagger}$ out, see below in Figure 7). In order to address this conundrum, we have employed methods of experimental (dynamic NMR) and computational chemistry (steered molecular dynamics, SMD) to inspect the relationship between the gates revolving at the rim of the host and the in/out exchange of guests. The results of our study suggest that for guests with a greater propensity to occupy the interior of the basket (i.e., more negative $\Delta G^{\circ}$ ) the process of gating is poorly synchronized with the guest exchange. The gates undergo a revolving motion to sweep the space but are concurrently less effective in enforcing the ejection of the guest from the cavity. Moreover, the results of dynamic ${ }^{1} \mathrm{H}$ NMR measurements of $\mathrm{CH}_{3} \mathrm{CCl}_{3}$ (2) entering and departing basket 1 (Figure 1) suggest the absence of an interchange mechanism [22] in which a molecule of
$\mathrm{CH}_{3} \mathrm{CCl}_{3}$ directly displaces another $\mathrm{CH}_{3} \mathrm{CCl}_{3}$ residing in the interior of the gated basket.

\section{Results and Discussion The encapsulation stoichiometry and the intrinsic binding $\left(\Delta G^{\circ}\right)$}

In an earlier study [13], we reported on the tendency of basket 1 to trap $\mathrm{CH}_{3} \mathrm{CCl}_{3}(2)$ as a guest, and we hereby elaborate on the equilibrium thermodynamics of the recognition event (Figure 2). The incremental addition of 2 to a $\mathrm{CD}_{2} \mathrm{Cl}_{2}$ solution of $1(0.67 \mathrm{mM}, 298.0 \mathrm{~K})$ caused considerable ${ }^{1} \mathrm{H}$ NMR chemical shifts of the resonances corresponding to the presence of the basket (Figure 2). At $298.0 \mathrm{~K}$, the formation and degradation of [basket- $\mathrm{CH}_{3} \mathrm{CCl}_{3}$ ] complex was sufficiently fast on the "NMR time scale": The nonlinear least-squares fitting of the binding isotherm to a $1: 1$ binding model provided $K_{\mathrm{a}}=54 \pm 1$ $\mathrm{M}^{-1}\left(R^{2}=0.998\right.$, Figure 2) [23].

Indeed, the results of a variable temperature ${ }^{1} \mathrm{H}$ NMR study (400 MHz, $\left.\mathrm{CD}_{2} \mathrm{Cl}_{2}\right)$ of $1(0.67 \mathrm{mM})$ containing $\mathrm{CH}_{3} \mathrm{CCl}_{3}$ (2) $(1.07 \mathrm{mM})$ was in line with the formation of the 1:1 complex; note that extrapolation of the fitted line gives $K_{\mathrm{a}}$ of $86 \pm 16 \mathrm{M}^{-1}$ at $298.0 \mathrm{~K}$, which is akin to the value obtained in the titration experiment. Furthermore, the van't Hoff analysis of the ${ }^{1} \mathrm{H}$ NMR data revealed that the encapsulation is also driven by enthalpy $\left(\Delta H^{\circ}=-3.56 \pm 0.06 \mathrm{kcal} / \mathrm{mol}\right.$, Figure 2$)$. Indeed, the computed electrostatic potential surface (AM1, Spartan) [20] of guest 2 is complementary to the one corresponding to the concave interior of 1 (Figure 1). Furthermore, compound 2 (93 $\AA^{3}$, Spartan) occupies $42 \%$ of the inner space of $1\left(221 \pm 9 \AA^{3}\right)$
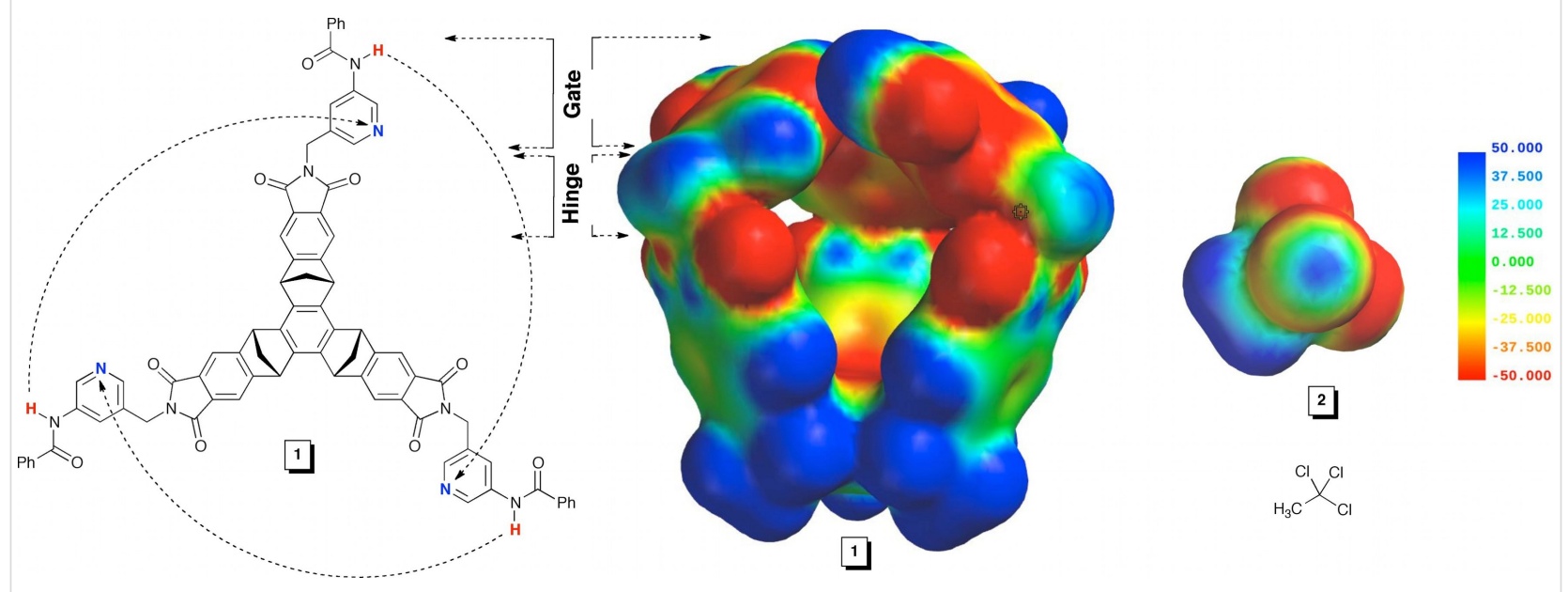

Figure 1: Chemical structure of gated molecular basket 1 and 1,1,1-trichloroethane (2). Electrostatic potential surfaces of basket 1 and guest 2 were computed with Spartan (AM1) [20]. 


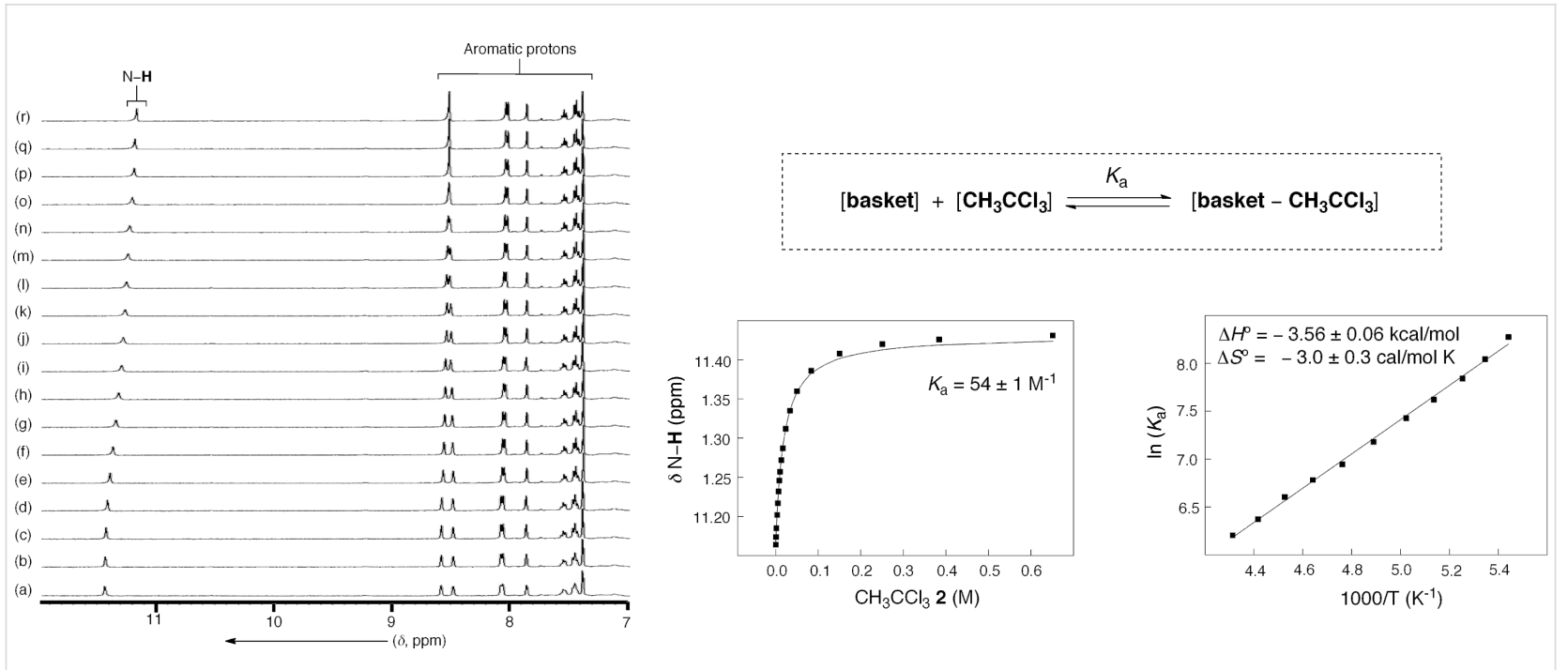

Figure 2: (Left): ${ }^{1} \mathrm{H}$ NMR spectra $\left(400 \mathrm{MHZ}, \mathrm{CD}_{2} \mathrm{Cl}_{2}\right)$ of $1(0.67 \mathrm{mM})$ obtained upon incremental addition of 1,1,1-trichloroethane $(2)(0.00-0.65 \mathrm{M})$ at 298.0 K. (Middle): Nonlinear least-squares fitting (SigmaPlot) of the $\mathbf{N}-\mathbf{H}$ chemical shift of $\mathbf{1}$ as a function of the concentration of 2 gave $K_{\mathrm{a}}=54 \pm 1$ $\mathrm{M}^{-1}$ at $298.0 \mathrm{~K}$ [23]. (Right): The van't Hoff plot was generated from variable temperature ${ }^{1} \mathrm{H} \mathrm{NMR}$ measurements $(400 \mathrm{MHz}, 180-250 \mathrm{~K})$ of 1 (0.67 $\mathrm{mM}$ ) containing $\mathrm{CH}_{3} \mathrm{CCl}_{3}(1.07 \mathrm{mM})$.

[11], which is close to the packing coefficient of liquids and thereby a good indicator of a stable assembly [24].

\section{The rate law characterizing guest exchange and the constrictive binding $\left(\Delta G^{\ddagger}\right.$ in/out $)$}

We performed ${ }^{1} \mathrm{H},{ }^{1} \mathrm{H}-\mathrm{EXSY}$ [25] and selective inversiontransfer [26,27] NMR measurements $\left(400 \mathrm{MHz}, \mathrm{CD}_{2} \mathrm{Cl}_{2}\right)$ to examine the rate laws characterizing the trafficking of $\mathrm{CH}_{3} \mathrm{CCl}_{3}$ (2) to and from basket 1 . At concentrations of $\mathrm{CH}_{3} \mathrm{CCl}_{3}$ as a guest comparable to those of host $\mathbf{1}$, the EXSY measurements
$(250.0 \pm 0.1 \mathrm{~K})$ allowed us to extract (MNova software) the magnetization rate coefficients $k^{*}$ in and $k^{*}$ out (Figure 3 ).

At higher concentrations of $\mathrm{CH}_{3} \mathrm{CCl}_{3}$ with respect to host $\mathbf{1}$, however, we noticed an intense $T_{1}$ noise coinciding with the $\left[\mathrm{CH}_{3} \mathrm{CCl}_{3}\right]_{\text {out }}$ signal, thus preventing the accurate determination of the volume of the corresponding cross peak. Accordingly, we had to turn to selective inversion-transfer NMR measurements to obtain the values of $k^{*}$ in and $k^{*}$ out. The exchange rate constants $k^{*}$ in and $k^{*}$ out (characterizing the longi-

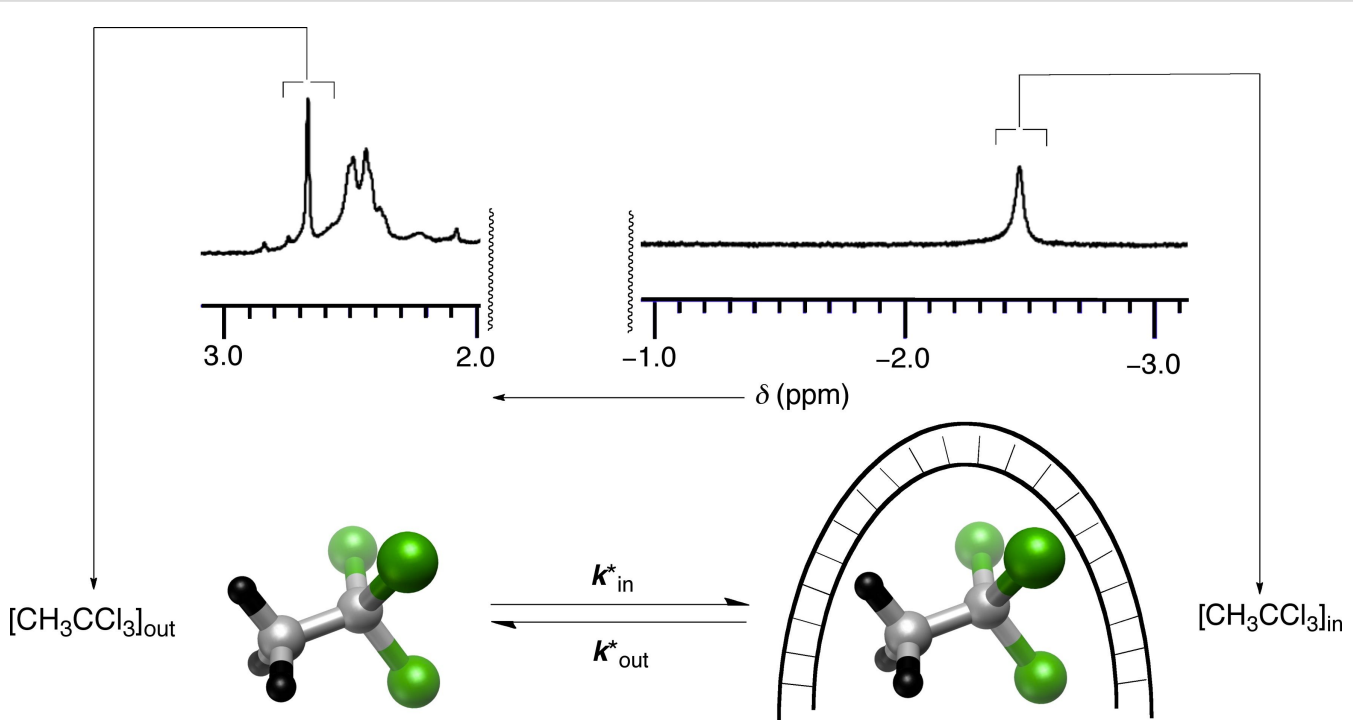

Figure 3: Chemically equivalent $\mathrm{CH}_{3}$ protons (black) in 1,1,1-trichloroethane (2) alter their magnetic environment from 2.70 ppm in bulk solvent to $-2.45 \mathrm{ppm}$ inside the basket. 
tudinal magnetization of the hydrogen nuclei in $\mathrm{CH}_{3} \mathrm{CCl}_{3}$ altering the chemical/magnetic environment) are by the nature of the experiment pseudo-first-order in character (see below) $[25,26]$.

On the basis of the reaction stoichiometry (Figure 2), we initially made the assumption that the entrapment is first-order in both [basket] and $\left[\mathrm{CH}_{3} \mathrm{CCl}_{3}\right]$. Accordingly, the rate of the forward reaction is given as:

$$
v_{\text {in }}=k_{\text {in }}[\text { basket }] \cdot\left[\mathrm{CH}_{3} \mathrm{CCl}_{3}\right]
$$

As per the earlier discussion, the pseudo-first-order constant $k^{*}$ in describes the longitudinal magnetization of the hydrogen nuclei in $\mathrm{CH}_{3} \mathrm{CCl}_{3}$ transferring from the bulk solvent $(\delta=2.70$ ppm, Figure 3$)$ to the interior of $\mathbf{1}(\delta=-2.45 \mathrm{ppm}$, Figure 3$)$.

Correspondingly, the rate of the forward reaction (entrapment) can be formulated as:

$$
v_{\text {in }}=k_{\text {in }}^{*}\left[\mathrm{CH}_{3} \mathrm{CCl}_{3}\right]
$$

From Equation 1 and Equation 2, we furthermore derive:

$$
\begin{aligned}
k_{\text {in }}[\text { basket }] \cdot\left[\mathrm{CH}_{3} \mathrm{CCl}_{3}\right] & =k_{\text {in }}^{*}\left[\mathrm{CH}_{3} \mathrm{CCl}_{3}\right] \\
k_{\text {in }}^{*} & =k_{\text {in }}[\text { basket }]
\end{aligned}
$$

If the proposed model is valid, then the experimentally determined $k^{*}$ in will be linearly proportional to the concentration of free basket 1 . Indeed, when the value of $k^{*}$ in is plotted against the concentration of free basket $\mathbf{1}$, there is an apparent linear dependence, with the slope of the fitted curve $k_{\text {in }}=2.1 \pm 0.3 \times$ $10^{3} \mathrm{M}^{-1} \cdot \mathrm{s}^{-1}$ (at $250 \pm 0.1 \mathrm{~K}$, Figure 4). Using Equation 4, we derive Equation 5, which upon insertion into Equation 3 gives Equation 6:

$$
\begin{gathered}
K_{\mathrm{a}}=\left[\text { basket }-\mathrm{CH}_{3} \mathrm{CCl}_{3}\right] /\left([\text { basket }] \cdot\left[\mathrm{CH}_{3} \mathrm{CCl}_{3}\right]\right) \\
{[\text { basket }]=\left[\text { basket }-\mathrm{CH}_{3} \mathrm{CCl}_{3}\right] /\left(K_{\mathrm{a}}\left[\mathrm{CH}_{3} \mathrm{CCl}_{3}\right]\right)} \\
k^{*}{ }_{\text {in }}=k_{\text {in }}\left[\text { basket }-\mathrm{CH}_{3} \mathrm{CCl}_{3}\right] /\left(K_{\mathrm{a}}\left[\mathrm{CH}_{3} \mathrm{CCl}_{3}\right]\right)
\end{gathered}
$$

This particular dependence suggests that $k^{*}$ in should be directly proportional to the concentration of the host-guest complex, [basket- $\mathrm{CH}_{3} \mathrm{CCl}_{3}$ ], but inversely proportional to the concentra- tion of $\mathrm{CH}_{3} \mathrm{CCl}_{3}$. At higher concentrations of $\mathrm{CH}_{3} \mathrm{CCl}_{3}$, however, there should be a negligible variation in the concentration of basket- $\mathrm{CH}_{3} \mathrm{CCl}_{3}$ and the magnetization rate coefficient $k^{*}$ in becomes inversely proportional to the concentration of $\mathrm{CH}_{3} \mathrm{CCl}_{3}$.

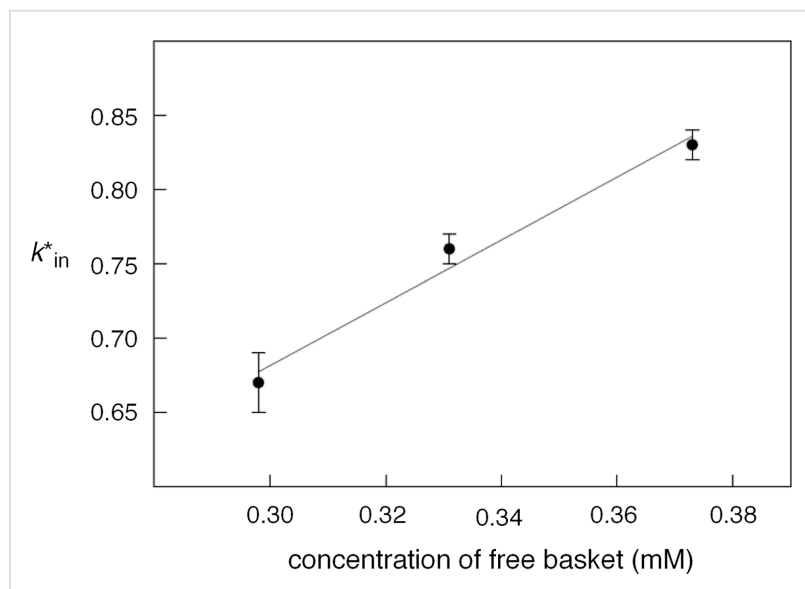

Figure 4: Nonlinear least-squares fitting (SigmaPlot) of magnetization rate constants $k^{*}$ in $(2$-D EXSY, $250.0 \pm 0.1 \mathrm{~K}$ ) as a function of the concentration of the free basket to a linear function gives a slope of $k_{\text {in }}$ $=2.1 \pm 0.3 \times 10^{3} \mathrm{M}^{-1} \cdot \mathrm{s}^{-1}$.

In accordance with this theoretical model, we completed a series of selective inversion-transfer [27] NMR measurements of $1(1.65 \mathrm{mM})$ and $\mathrm{CH}_{3} \mathrm{CCl}_{3}(16-200 \mathrm{mM})$ in $\mathrm{CD}_{2} \mathrm{Cl}_{2}$ at 250.0 $\pm 0.1 \mathrm{~K}$ (Figure 5). In the experiment, the proton resonance corresponding to $\left[\mathrm{CH}_{3} \mathrm{CCl}_{3}\right]_{\text {out }}$ was selectively inverted, resulting in the perturbation of the longitudinal relaxation of both $\left[\mathrm{CH}_{3} \mathrm{CCl}_{3}\right]_{\text {out }}$ and $\left[\mathrm{CH}_{3} \mathrm{CCl}_{3}\right]_{\text {in }}$ due to chemical exchange over the course of variable delay time $\tau\left(180^{\circ} \mathrm{x}\right.$ (selective) $-\tau-$ $90^{\circ} \mathrm{x}$ (nonselective) $-\tau_{\mathrm{d}}$ ). Upon the integration of both signals ( $\mathrm{I}_{\text {in }}$ and $\mathrm{I}_{\text {out }}$ ), we subjected the data to nonlinear least-squares fitting of $\mathrm{I}_{\text {in/out }}$ versus $\tau$ using the proposed solutions of the McConnell equations [27] describing the relaxation of the hydrogen nucleus residing in two environments (Figure 5A). For the fitting, the longitudinal relaxation rate $\left(1 / T_{1}\right)$ of hydrogen nuclei in $\mathrm{CH}_{3} \mathrm{CCl}_{3}$ was determined separately by using a classical selective inversion-recovery NMR pulse sequence. When the experimental $k^{*}$ in was plotted against the equilibrium concentration of $\mathrm{CH}_{3} \mathrm{CCl}_{3}$, there indeed appeared a hyperbolic dependence (Figure 5B) in agreement with Equation $6\left(k^{*}{ }_{\text {in }} \propto 1 /\left[\mathrm{CH}_{3} \mathrm{CCl}_{3}\right]\right)$. The fitting of the data to Equation 6 was inaccurate as only a few experimental points characterize the dependence (Figure 5B), although computing $k_{\text {in }}$ from each data point would give a value of this coefficient $\left(\sim 2 \times 10^{3} \mathrm{M}^{-1} \cdot \mathrm{s}^{-1}\right)$ similar to that determined in the EXSY experiment (Figure 4). In accordance with the 2-D EXSY and selective inversion-transfer results, we conclude that the entrapment is first-order in both basket $\mathbf{1}$ and guest $\mathbf{2}$. 
(A)

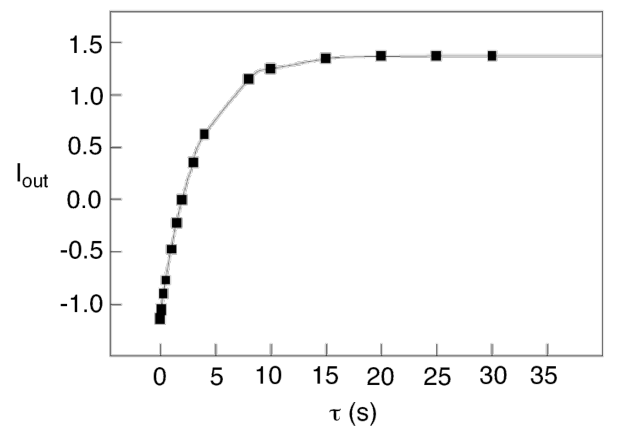

(B)

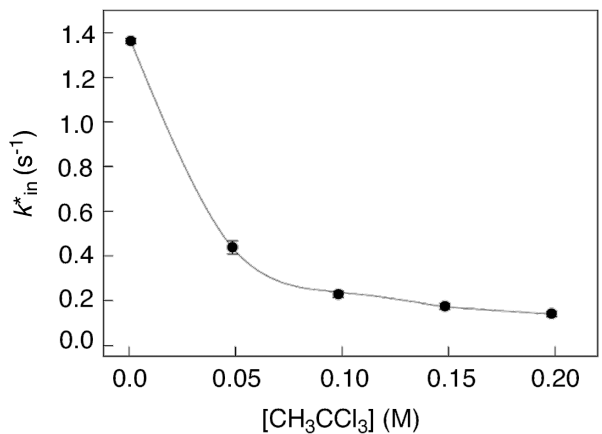

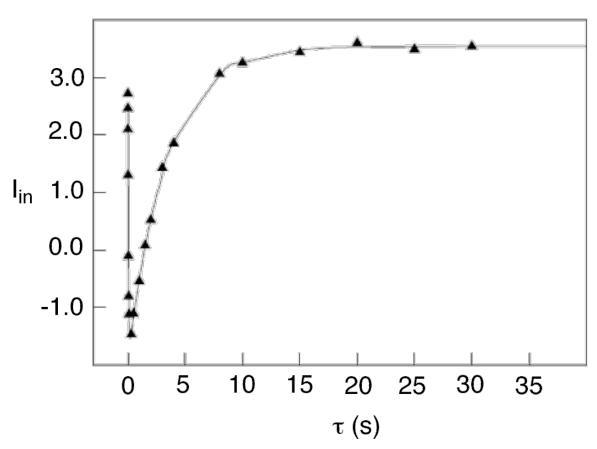

(C)

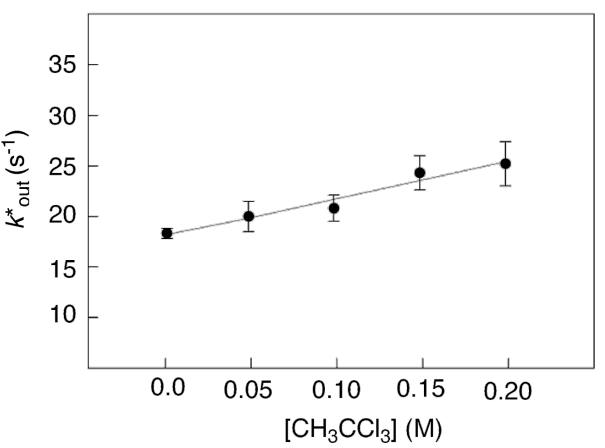

Figure 5: (A): Nonlinear least-squares fitting of ${ }^{1} \mathrm{H}$ NMR signal intensities $\left(\mathrm{l}_{\text {in/out }}\right)$ of $\left[\mathrm{CH}_{3} \mathrm{CCl}_{3}\right]_{\text {in/out }}$ as function of the time variable $\mathrm{T}(250.0 \pm 0.1 \mathrm{~K})$ was completed with the assistance of the Bloch-McConnell equations $[27,28]$ describing the relaxation of hydrogen nuclei in two different environments; in this particular experiment [basket] $]_{0}=1.65 \mathrm{mM}$ and $\left[\mathrm{CH}_{3} \mathrm{CCl}_{3}\right]_{0}=50.0 \mathrm{mM}$. Magnetization transfer rate coefficients $k^{*}{ }_{\text {in }}(\mathrm{B})$ and $k^{*}{ }_{\text {out }}(\mathrm{C})$ were further obtained $[27,28]$ from selective inversion-transfer measurements and plotted as a function of the concentration of free $\mathrm{CH}_{3} \mathrm{CCl}_{3}$.

On the basis of the reaction stoichiometry (Figure 2), the rate law for $\mathbf{2}$ leaving the encapsulation complex can be described as:

$$
v_{\text {out }}=k_{\text {out }}\left[\text { basket }-\mathrm{CH}_{3} \mathrm{CCl}_{3}\right]
$$

Alternatively, the rate of the same process expressed through the NMR magnetization transfer rate coefficient $k^{*}$ out is:

$$
v_{\text {out }}=k_{\text {out }}^{*}\left[\text { basket }-\mathrm{CH}_{3} \mathrm{CCl}_{3}\right]
$$

As in the case above, the manipulation of Equation 7 and Equation 8 gives Equation 9:

$$
k^{*}{ }_{\text {out }}=k_{\text {out }}
$$

In accordance with this theoretical model, we increased the concentration of guest $2(16-200 \mathrm{mM})$ with respect to $\mathbf{1}(1.65$ $\mathrm{mM})$ and measured $k^{*}$ out using the selective inversion-transfer
NMR pulse sequence. Markedly, there was essentially no interdependence between $k^{*}$ out $\left(21 \pm 3 \mathrm{~s}^{-1}\right)$ and the concentration of guest 2 (Figure 5C); the curve indeed shows a small slope, but the intercept of 18.1 suggests that this is likely an artifact. 2-D EXSY measurements would give a rate coefficient $k^{*}{ }_{\text {out }}=10 \pm$ $0.1 \mathrm{~s}^{-1}$, which was also found to be independent of the external concentration of the basket/guest (Figure 4). The departure of $\mathrm{CH}_{3} \mathrm{CCl}_{3}$ from its complexed form [basket- $\mathrm{CH}_{3} \mathrm{CCl}_{3}$ ], therefore, follows a dissociative mechanism [4]. Notably, a molecule of solvent $\mathrm{CD}_{2} \mathrm{Cl}_{2}$ and not another $\mathrm{CH}_{3} \mathrm{CCl}_{3}$ (interchange mechanism) displaces the encapsulated guest. In fact, the inspection of CPK models as well as molecular dynamics studies (see below) revealed that the departure of $\mathrm{CH}_{3} \mathrm{CCl}_{3}$ (93 $\AA^{3}$ ) demands (a) "opening" of at least two gates, (b) disruption of internal $\mathrm{N}-\mathrm{H}^{\cdots} \mathrm{N}$ hydrogen bonds, and (c) distortion of the framework of the basket. We further reason that in the case of a direct exchange of two $\mathrm{CH}_{3} \mathrm{CCl}_{3}$ molecules, the departure of $\mathrm{CH}_{3} \mathrm{CCl}_{3}$ would create an empty host, and therefore vacuum, before another guest of the same kind can take its place. Note that two large compounds (overall $\sim 186 \AA^{3}$ ) cannot simultaneously occupy the interior of $\mathbf{1}\left(\sim 220 \AA^{3}\right)$. 


\section{Computational examination of the in/out traf- ficking}

To gain mechanistic insight into the departure of $\mathrm{CH}_{3} \mathrm{CCl}_{3}$ (2) from the interior of basket $\mathbf{1}$, we completed a series of steered molecular dynamics (SMD) simulations using the AMBER 10.0 suite of programs [29-32]. Without applying any external force on the entrapped $\mathrm{CH}_{3} \mathrm{CCl}_{3}$, we first found that this guest would, within $10 \mathrm{~ns}$, adopt many positions inside host $\mathbf{1}$, although the one depicted in Figure 6A is obtained after $1 \mathrm{~ns}$ (Supporting Information File 1). The $\mathbf{N}-\mathbf{H} \cdots \mathbf{N}$ hydrogen bond contacts along the top of the basket were also monitored throughout the $10 \mathrm{~ns}$ simulation. Importantly, the distance between each pair of amide-hydrogen and pyridine-nitrogen atoms was found to be invariant ( $\sim 2 \AA$, see Supporting Information File 1).

In addition, the width of each side aperture (the span between adjacent carbonyl oxygen atoms) also remained constant at $\sim 6.3 \AA$ throughout the simulation (Figure S3, see Supporting Information File 1). We then selected multiple trajectories for "pulling" the guest from the host (Figure 6A). Markedly, the departure of $\mathrm{CH}_{3} \mathrm{CCl}_{3}$ necessitated the cleavage of at least two intramolecular $\mathrm{N}-\mathbf{H} \cdots \mathrm{N}$ hydrogen bonds in $\mathbf{1}$ (Figure $6 \mathrm{~B}$ ) with a simultaneous expansion of the host (Figure 6B). That is to say, the "slippage" of $\mathrm{CH}_{3} \mathrm{CCl}_{3}$ (with gates in the "closed" position) does not appear to be a viable mechanistic scenario. Note that our simulation did not include solvent molecules $\left(\mathrm{CD}_{2} \mathrm{Cl}_{2}\right)$ displacing the entrapped $\mathrm{CH}_{3} \mathrm{CCl}_{3}$, as suggested by the kinetic study. The substitution of the guest by the solvent should perhaps cause an even greater distortion of the framework of the basket.

\section{The revolving of the gates and the racemiza- tion of basket 1}

The aromatic gates in basket $\mathbf{1}$ interact through hydrogen bonding, as exemplified by a large downfield shift of the signal corresponding to $(\mathrm{O}=\mathrm{C}) \mathrm{N}-\mathbf{H}$ protons $(\delta=11.6 \mathrm{ppm}$ at $298.0 \mathrm{~K}$, Figure 2) [13]. In addition, the aromatic gates are dynamic, each one revolving about its axis to give rise to two enantiomeric conformers $\mathbf{1}_{\mathbf{A}}$ and $\mathbf{1}_{\mathbf{B}}$ (Figure 7A). The interconversion kinetics of the $\mathbf{1}_{\mathbf{A} / \mathbf{B}}$ racemization can be followed by dynamic NMR spectroscopy in which a singlet corresponding to $\mathbf{H}_{\mathrm{a}} / \mathbf{H}_{\mathrm{b}}$ nuclei at high temperatures is seen to split into two doublets at low temperatures. In particular, the revolving rate of the gates is temperature dependent, thereby governing the lifetime of $\mathbf{H}_{\mathrm{a}}$ or $\mathbf{H}_{\mathrm{b}}$ nuclei, each residing in a particular chemical environment $(\tau$ $=1 / k_{\text {rac }}$ ); the hydrogen nuclei are observed as separate resonances when $\tau>>1 / \Delta v\left(\mathrm{H}_{\mathrm{a} / \mathrm{b}}\right)$ [33]. Accordingly, we performed the classical line-shape analysis of $\mathbf{H}_{\mathrm{a}} / \mathbf{H}_{\mathrm{b}}$ resonances (WinDNMR-Pro software) to obtain the rate constants $\left(k_{\text {rac }}\right)$ and corresponding activation energies $\Delta G^{\ddagger}$ rac characterizing the racemization of basket 1 (Figure $7 \mathrm{~B}$ ). Evidently, the rate at which the aromatic gates in $\mathbf{1}$ revolve is a function of the com-
(A)

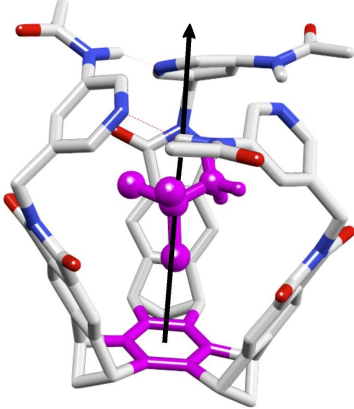

"pull up"

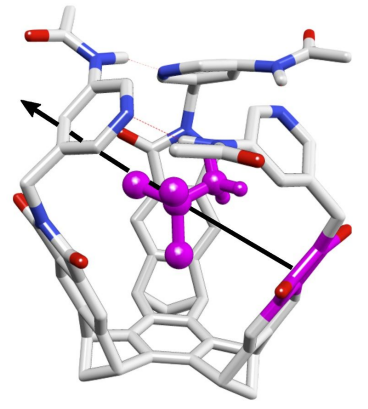

"pull on the side"

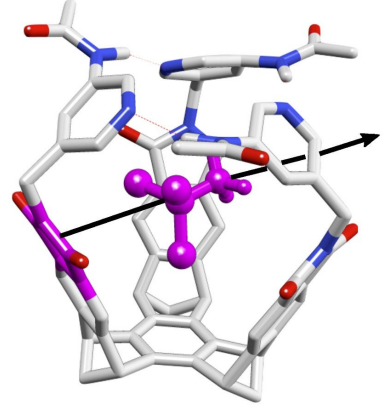

"pull on the side"

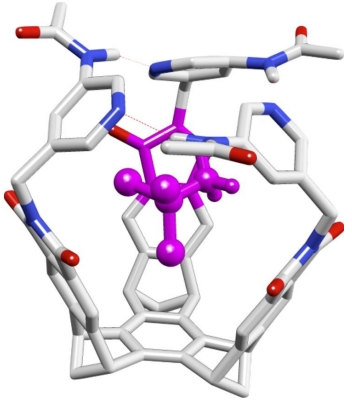

"pull on the side"

(B)
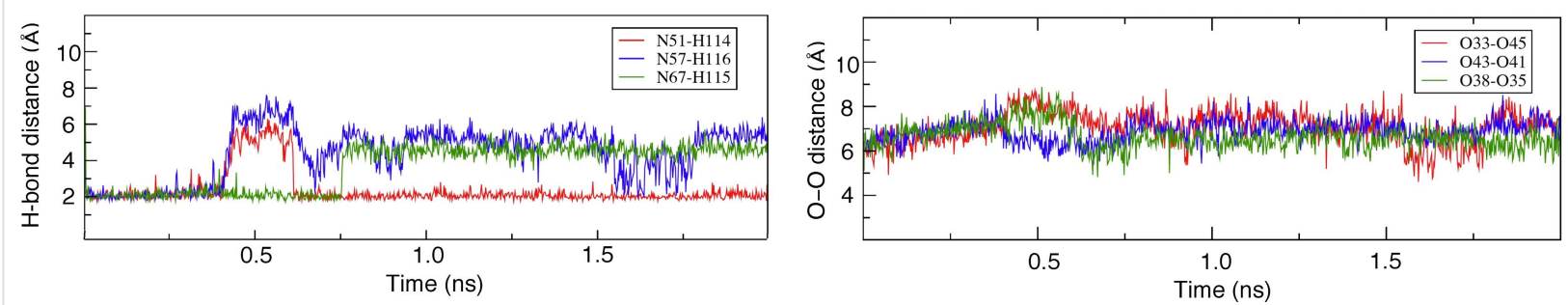

Figure 6: (A) Four different trajectories were used for examining the departure of $\mathrm{CH}_{3} \mathrm{CCl}_{3}$ guest from basket 1 with steered molecular dynamics. (B) The variation in $\mathrm{N}-\mathbf{H} \cdots \mathbf{N}$ and $-\mathrm{C}=\mathbf{O} \cdots \mathbf{O}=\mathrm{C}-$ distances during $\mathrm{SMD}$ simulation with $\mathrm{CH}_{3} \mathrm{CCl}_{3}$ being pulled on the side. 
(A)

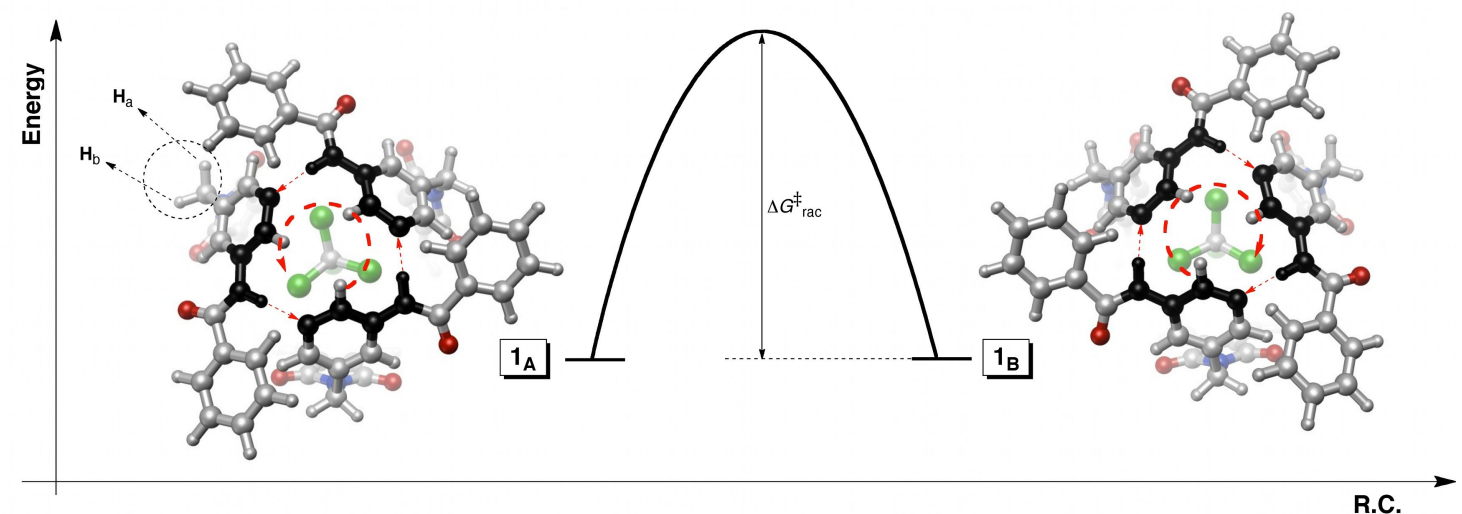

(B)



\begin{tabular}{|c|c|c|}
\hline & \multicolumn{2}{|c|}{$k_{r a c}\left(\mathrm{~s}^{-1}\right)$} \\
\hline & $\mathrm{CH}_{3} \mathrm{CCl}_{3}$ & $\mathrm{CD}_{2} \mathrm{Cl}_{2}$ \\
\hline \multirow[t]{3}{*}{$250.0 \mathrm{~K}$} & 308 & $\sim 48500$ \\
\hline & \multicolumn{2}{|c|}{$\Delta G_{\mathrm{rac}}^{\ddagger}(\mathrm{kcal} / \mathrm{mol})$} \\
\hline & $\mathrm{CH}_{3} \mathrm{CCl}_{3}$ & $\mathrm{CD}_{2} \mathrm{Cl}_{2}$ \\
\hline $250.0 \mathrm{~K}$ & 11.70 & 9.19 \\
\hline
\end{tabular}

Figure 7: (A) The interconversion of conformational enantiomers $1_{A}$ and $1_{B}$, having anticlockwise and clockwise senses in the orientation of the intramolecular $\mathrm{N}-\mathrm{H} \cdots \mathrm{N}$ hydrogen bonds, contributes to the process of racemization, i.e., the opening and closing of the basket [13]. (B) Eyring plots describing the linear relationship between $\ln \left(k_{\mathrm{rac}} \mathrm{T}\right)$ and temperature for basket 1 containing $\mathrm{CH}_{3} \mathrm{CCl}_{3}$ (black squares) and solvent $\mathrm{CD}_{2} \mathrm{Cl}_{2}$ (red triangles). The plots were generated from the results of the line-shape analysis (WinDNMR-Pro) of ${ }^{1} \mathrm{H} \mathrm{NMR} \mathrm{H}_{\mathrm{a} / \mathrm{b}}$ signals of $1\left(1.65 \mathrm{mM}, \mathrm{CD}_{2} \mathrm{Cl}_{2}\right.$ ) at variable temperatures.

pound occupying the inner space: With $\mathrm{CH}_{3} \mathrm{CCl}_{3}$ the gates are less dynamic than with $\mathrm{CD}_{2} \mathrm{Cl}_{2}$ occupying the cavity (Figure 7B).

\section{On the action mechanism of the basket}

Is there a relationship between the aromatic gates sweeping the space and guests trafficking to and from the basket [11]? That is to say, will the gates expel the entrapped guest each time that they alter their propeller-like orientation (Figure 8)? First, our kinetic measurements suggest that guest $\mathrm{CH}_{3} \mathrm{CCl}_{3}$ (2) enters basket 1 by substituting solvent $\left(\mathrm{CD}_{2} \mathrm{Cl}_{2}\right)$ molecule(s), while exactly the opposite occurs during the dissociation (Figure 8). Given this exchange scenario, we deduce that $\mathbf{1}_{\mathbf{A}}-\mathrm{CH}_{3} \mathrm{CCl}_{3}$ shall transform into $\mathbf{1}_{\mathrm{B}}-\mathrm{CH}_{3} \mathrm{CCl}_{3}$ via intermediate $\mathbf{1}-\mathrm{CD}_{2} \mathrm{Cl}_{2}$ (Figure 8). That is, the formation of $1-\mathrm{CD}_{2} \mathrm{Cl}_{2}$ from $\mathbf{1}_{\mathbf{A}}-\mathrm{CH}_{3} \mathrm{CCl}_{3}$ is accompanied by either reorientation or reinstatement of the gates, and therefore, there is an equal likelihood that $\mathbf{1}-\mathrm{CD}_{2} \mathrm{Cl}_{2}$ will yield $\mathbf{1}_{\mathbf{A}}-\mathrm{CH}_{3} \mathrm{CCl}_{3}$ or $\mathbf{1}_{\mathbf{B}}-\mathrm{CH}_{3} \mathrm{CCl}_{3}$ (Figure 8); this reasoning is also supported by the fact that the gates of the solvated basket revolve at a higher rate (Figure 7B) In accordance with such a racemization mechanism, we apply the statistical correction to the measured $k_{\mathrm{rac}}$ to obtain $k_{\mathrm{rac}^{\prime}}\left(k_{\mathrm{rac}}\right.$ $=2 k_{\mathrm{rac}}=616 \mathrm{~s}^{-1}$, Figure 7B) [34]. This particular rate coefficient should more precisely describe the process of racemization.

One could describe the free energy characterizing the guest departure $\left(\Delta G^{\ddagger}\right.$ out $)$ as a linear combination of $\Delta G^{\ddagger} \mathrm{rac}^{\prime}+\Delta G^{\circ}+$ $\Delta G^{\ddagger}$ sterics representing (1) the opening of the gates $\left(\Delta G^{\ddagger}\right.$ rac'), (2) the decomplexation of the guest $\left(\Delta G^{\circ}\right)$, and (3) the "slippage" of the guest while exiting the open host $\left(\Delta G^{\star}\right.$ sterics $)$ $[8,11,21,35]$. The encapsulation kinetics is first-order in guest $\mathrm{CH}_{3} \mathrm{CCl}_{3}$ suggesting that this species creates van der Waals strain (friction) during the in/out trafficking, thereby justifying the use of the $\Delta G^{\ddagger}$ sterics term.

In addition, the decomplexation of $\mathrm{CH}_{3} \mathrm{CCl}_{3}$ follows a late transition state [14] whereby its affinity for populating the interior of the basket should decrease to a somewhat smaller value than described by $\Delta G^{\circ}$. Given the delicacy of the proposed partitioning, will the additivity of free energies and the relationship $\Delta G^{\ddagger} \mathrm{rac}^{\prime}+\Delta G^{\circ}+\Delta G^{\ddagger}$ sterics $\sim \Delta G_{\text {out }}^{\ddagger}$ still hold? 


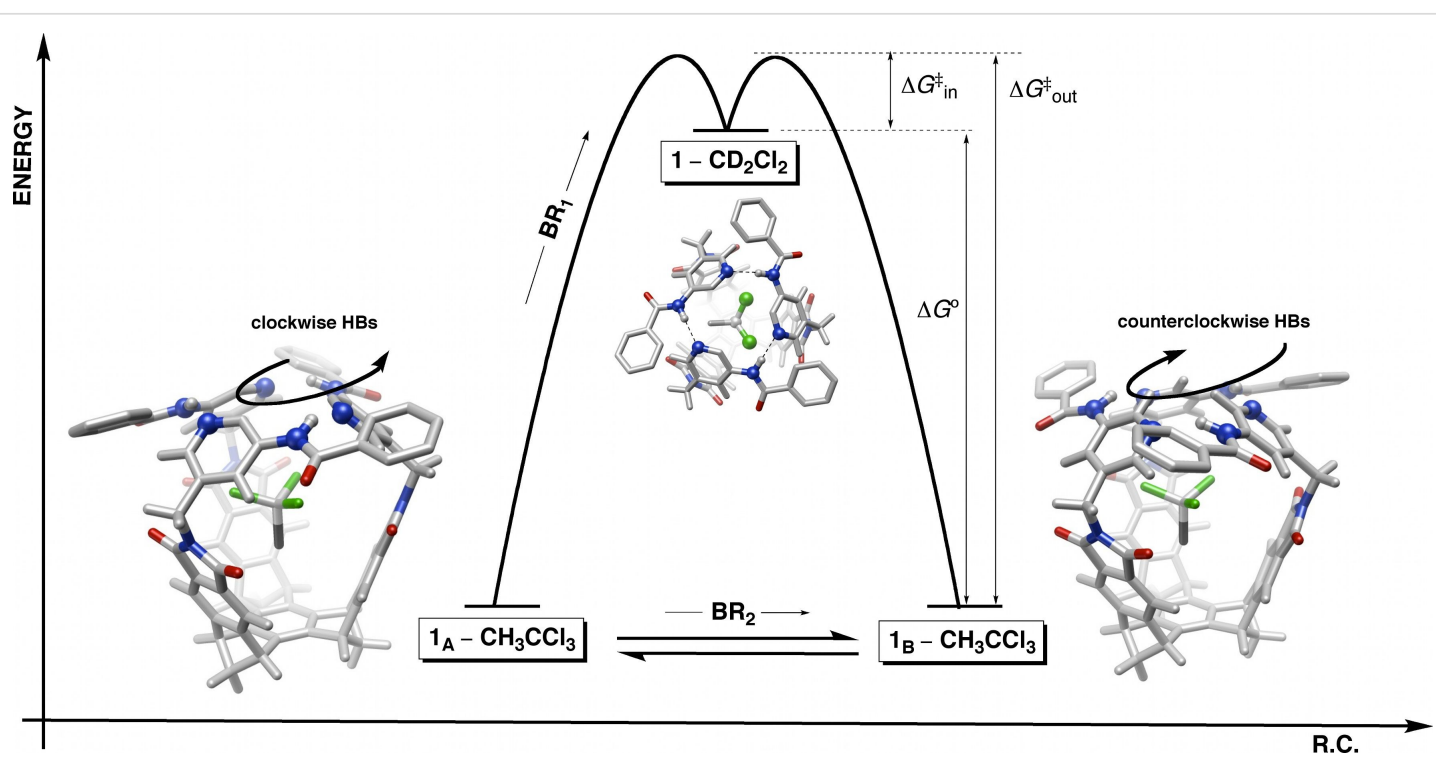

Figure 8: The departure of $\mathrm{CH}_{3} \mathrm{CCl}_{3}$ from $1_{\mathrm{A}}-\mathrm{CH}_{3} \mathrm{CCl}_{3}$ gives rise to the less stable 1- $\mathrm{CD}_{2} \mathrm{Cl}_{2}$, which upon entrapment of another $\mathrm{CH}_{3} \mathrm{CCl}_{3}$ gives either $1_{\mathrm{A}}-\mathrm{CH}_{3} \mathrm{CCl}_{3}$ or $1_{\mathrm{B}}-\mathrm{CH}_{3} \mathrm{CCl}_{3}$. The $1_{\mathrm{A} / \mathrm{B}}-\mathrm{CH}_{3} \mathrm{CCl}_{3}$ interconversion occurs with $\mathrm{CH}_{3} \mathrm{CCl}_{3}$ departing $\left(\mathrm{BR}_{1}\right.$ mechanism) or remaining (BR2 mechanism) in the cavity.

When $\Delta G^{\ddagger} \mathrm{rac}^{\prime}$ of $11.4 \pm 0.1 \mathrm{kcal} / \mathrm{mol}$ (at $250.0 \pm 0.1 \mathrm{~K}$, Figure 7) is added to the intrinsic binding energy of $\mathrm{CH}_{3} \mathrm{CCl}_{3}$ $\left(\left|\Delta G^{\circ}\right|=2.79 \pm 0.09 \mathrm{kcal} / \mathrm{mol}\right.$ at $250.0 \pm 0.1 \mathrm{~K}$, Figure 2), a value of $14.2 \mathrm{kcal} / \mathrm{mol}$ is obtained. Without even including $\Delta G^{\ddagger}$ sterics (as a positive number), there is an apparent disagreement between the sum value $(\geq 14.2 \mathrm{kcal} / \mathrm{mol})$ and the experimentally determined $\Delta G^{\ddagger}$ out $=13.4 \pm 0.1 \mathrm{kcal} / \mathrm{mol}$ (from 2-D EXSY, $\left.k_{\text {out }}=10 \pm 1 \mathrm{~s}^{-1}\right)$. Is there a missing factor needed in order to understand this phenomenon?

In reality, when the internal hydrogen bonds are broken and the gates open up the guest does not have to depart the basket cavity. That is to say, the gates should be able to revolve to allow the interconversion of $\mathbf{1}_{\mathbf{A}}-\mathrm{CH}_{3} \mathrm{CCl}_{3}$ into $\mathbf{1}_{\mathrm{B}}-\mathrm{CH}_{3} \mathrm{CCl}_{3}$ without even ejecting the guest. Accordingly, we hereby propose that the conversion of $\mathbf{1}_{\mathbf{A}}-\mathrm{CH}_{3} \mathrm{CCl}_{3}$ into $\mathbf{1}_{\mathrm{B}}-\mathrm{CH}_{3} \mathrm{CCl}_{3}$ (i.e., racemization) occurs by two routes, $\mathrm{BR}_{1}$ and $\mathrm{BR}_{2}$, one with $\left(\mathrm{BR}_{1}\right)$ and another without $\left(\mathrm{BR}_{2}\right)$ the concomitant guest exchange (Figure 8).

It follows that, during the departure of $\mathrm{CH}_{3} \mathrm{CCl}_{3}$, the measured racemization of $\mathbf{1}\left(\Delta G_{\mathrm{rac}^{\prime}}\right)$ includes energetic contributions from two pathways ( $\Delta G^{\ddagger}{ }_{\mathrm{rac}^{\prime}}=\Delta G_{\mathrm{BR} 1}^{\ddagger}+\Delta G_{\mathrm{BR} 2}^{\ddagger}$ ) of which only $\mathrm{BR}_{1}$ should be incorporated in the additivity assessment. It is therefore convenient to partition the energetic contribution of the two “competing” $\mathrm{BR}_{1}$ and $\mathrm{BR}_{2}$ routes to $\Delta G^{\ddagger} \mathrm{rac}^{\prime}\left(\Delta G^{\ddagger} \mathrm{rac}^{\prime}=\Delta G^{\ddagger} \mathrm{BR} 1\right.$ $+\Delta G^{\ddagger} \mathrm{BR} 2$ ) to corroborate fully the role of the gates. However, this is a difficult task, but for guest molecules holding strongly onto the basket (more negative $\Delta G^{\circ}$ ) there should be a greater contribution from the $\mathrm{RG}_{2}$ pathway during the racemization.
In one of our prior studies [13,14], we measured kinetic and thermodynamic parameters pertaining to the exchange of five isosteric (same-size) guests 3-7 to and from basket 1 (Figure 9). When $\Delta G^{\ddagger} \mathrm{rac}^{\prime}+\Delta G^{\circ}$ is computed for each guest and the values plotted against $\Delta G^{\ddagger}$ out, a linear relationship appears $\left(R^{2}=0.99\right.$, Figure 9A). Note that $\Delta G^{\ddagger}$ sterics is not included in this analysis as it is unknown; however, we anticipate that the value of the parameter should show minimal fluctuations for the series of isosteric guests 3-7. Importantly, the greater the affinity of a particular guest for occupying the interior of the basket $\left(\Delta G^{\circ}\right)$, the greater the deviation of the calculated $\Delta G^{\ddagger} \mathrm{rac}^{\prime}+\Delta G^{\circ}$ (black line, Figure 9A) from the experimental $\Delta G^{\ddagger}$ out (red line, Figure 9A). The variation of $\Delta \Delta G=\left(\Delta G^{\star}{ }_{\mathrm{rac}^{\prime}}+\Delta G^{\circ}\right)-\Delta G^{\dagger}$ out with intrinsic binding energies $\Delta G^{\circ}$ of 3-7 is shown in Figure 9B. The trend is evident, supporting the notion that for guests having greater propensity to occupy the basket $\left(\Delta G^{\circ}\right)$ the $\mathrm{BR}_{2}$ pathway is more greatly involved in the $\mathbf{1}_{\mathbf{A}}-\mathrm{CH}_{3} \mathrm{CCl}_{3}$ / $\mathbf{1}_{\mathbf{B}}-\mathrm{CH}_{3} \mathrm{CCl}_{3}$ racemization. As already discussed, the $\mathrm{BR}_{2}$ pathway contributes to the measured $\Delta G^{\ddagger}{ }_{\text {rac }}$, yet it is not involved in the exchange of guests.

\section{Conclusion}

Describing mechanisms by which dynamic hosts entrap/release guests is a challenging task necessitating experimental and computational scrutiny. Notably, one can use NMR spectroscopic methods for understanding the equilibrium kinetics characterizing the rate law of molecular encapsulation processes. Our study, accordingly, describes the rate law characterizing the encapsulation of guest $\mathrm{CH}_{3} \mathrm{CCl}_{3}$ by the gated basket 1 . Importantly, the entrapment reaction is first-order in each compound, 
(A)

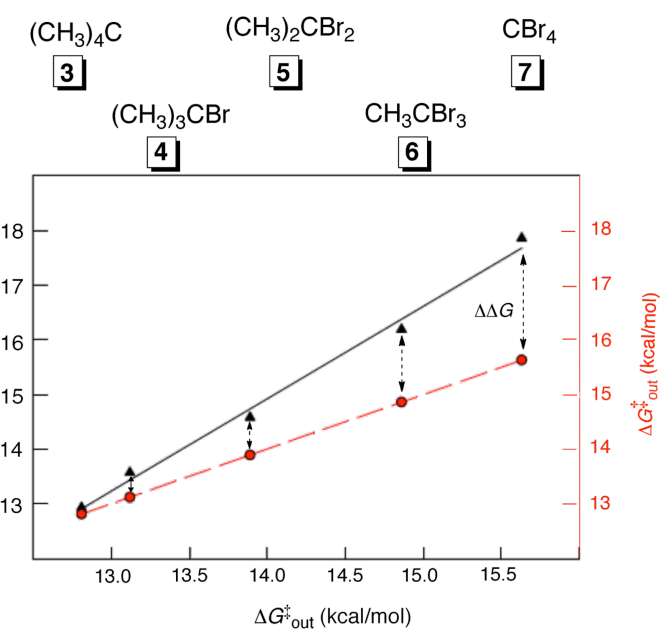

(B)

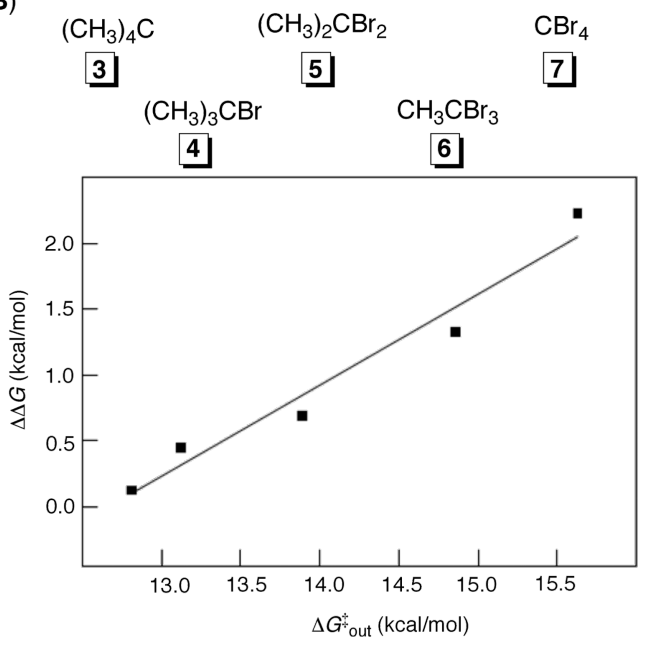

Figure 9: $(A)$ : Kinetic and thermodynamic parameters [13,14] characterizing the departure of isosteric guests 3-7 from the basket. (B): The computed $\Delta \Delta G=\left(\Delta G^{\ddagger}\right.$ rac $\left.^{\prime}+\Delta G^{\circ}\right)-\Delta G^{\ddagger}$ out is apparently a linear function of $\Delta G^{\ddagger}$ out.

while the complex dissociation is zeroth-order in guest $\mathrm{CH}_{3} \mathrm{CCl}_{3}$. Furthermore, examination of the additivity of free energies corresponding to different molecular events can assist in the understanding of the operation of gated hosts and, in particular, can help to reveal the explicit role of the gates. On the basis of these results, we deduced that the synchronicity in the revolving motion of the gates and in/out trafficking of guests is a function of the affinity of the guest for occupying the gated basket. The greater the affinity, the less effective the gates are in "sweeping" the guest as the gates undergo their revolving motion. This result is important for exploring the utility of gating for controlling the outcome of chemical reactions occurring in confined space but also for the understanding of the effective conversion of energy at the molecular level and the preparation of molecular machines [36,37].

\section{Experimental}

Procedure for 2-D EXSY experiments [25]: A solution of basket 1 and guest 2 in $\mathrm{CD}_{2} \mathrm{Cl}_{2}$ (J. Young NMR tube) was cooled to $250.0 \pm 0.1 \mathrm{~K}$ inside the NMR probe and allowed to equilibrate for $1.0 \mathrm{~h}$. A series of gradient NOESY experiments was run with a relaxation delay of $5 \times T_{1}$ and mixing times $\left(\tau_{\mathrm{m}}\right)$ of $0 \mathrm{~ms}$ and three others ranging from $40 \mathrm{~ms}$ to $250 \mathrm{~ms}$, such that the cross-peaks were clearly resolved; the spin-lattice relaxation time $\left(T_{1}=3.30 \mathrm{~s}\right)$ for the free guest was determined by performing a standard inversion-recovery pulse sequence with a relaxation delay $\left(\tau_{\mathrm{d}}\right)$ of at least $5 \times T_{1}$. Each of the $128 \mathrm{~F}_{1}$ increments represented the accumulation of at least two scans. The corresponding integrals were determined by using MNova software from Mestrelab Research, after phase and baseline corrections in both dimensions. The magnetization exchange rate constants $\left(k^{*}\right.$ in and $k^{*}$ out $)$ were, at each mixing time $\tau_{\mathrm{m}}$, calculated by using the EXSYCalc program (Mestrelab Research). The mean values of $k^{*}$ in and $k^{*}{ }_{\text {out }}$ are reported with the standard deviation as an experimental error.

\section{Procedure for ${ }^{\mathbf{1}} \mathrm{H}$-selective inversion-transfer experiments} [27]: A solution of basket 1 and guest $\mathbf{2}$ in $\mathrm{CD}_{2} \mathrm{Cl}_{2}$ (J. Young NMR tube) was cooled to $250.0 \pm 0.1 \mathrm{~K}$ inside the NMR probe and allowed to equilibrate for $1.0 \mathrm{~h}$. The ${ }^{1} \mathrm{H}$ spin-lattice relaxation time $\left(T_{1}=3.30 \mathrm{~s}\right)$ for the free guest was determined by a standard inversion-recovery pulse sequence with a relaxation delay $\left(\tau_{\mathrm{d}}\right)$ of at least $5 \times T_{1}$. By using a selective 1-D inversionrecovery pulse sequence $\left[180^{\circ} \times\right.$ (selective) $-\tau-90^{\circ} \times$ (nonselective) $-\tau_{d}$ ], 32 transients were obtained for each variable delay time $(\tau)$ with a relaxation delay $\left(\tau_{\mathrm{d}}\right)$ of at least $5 \times T_{1}$. The absolute integrals corresponding to encapsulated and free guest molecules were, at each mixing time, determined by using TopSpin software from Bruker, and the resulting data was fitted by using the two-site exchange equations described by Led et al. [27] to obtain magnetization exchange rate constants $k^{*}{ }_{\text {in }}$ and $k^{*}$ out.

\section{Supporting Information}

Supporting Information contains details of the computational studies.

\section{Supporting Information File 1}

Details of the computational studies.

[http://www.beilstein-journals.org/bjoc/content/ supplementary/1860-5397-8-9-S1.pdf] 


\section{Acknowledgements}

This work was financially supported with funds obtained from the National Science Foundation under CHE-1012146 (to J.D.B.). We thank the Ohio Supercomputer Center for generous allocations of computational resources.

\section{References}

1. Badjić, J. D.; Stojanović, S.; Ruan, Y. Adv. Phys. Org. Chem. 2011, 45, 1. doi:10.1016/B978-0-12-386047-7.00001-1

2. Hof, F.; Craig, S. L.; Nuckolls, C.; Rebek, J., Jr. Angew. Chem., Int. Ed. 2002, 41, 1488.

doi:10.1002/1521-3773(20020503)41:9<1488::AID-ANIE1488>3.0.CO; 2-G

3. Palmer, L. C.; Rebek, J., Jr. Org. Biomol. Chem. 2004, 2, 3051. doi:10.1039/b412510j

4. Rieth, S.; Hermann, K.; Wang, B.-Y.; Badjić, J. D. Chem. Soc. Rev. 2011, 40, 1609. doi:10.1039/c005254j

5. Pluth, M. D.; Raymond, K. N. Chem. Soc. Rev. 2007, 36, 161. doi:10.1039/b603168b

6. Davis, A. V.; Raymond, K. N. J. Am. Chem. Soc. 2005, 127, 7912. doi:10.1021/ja051037s

7. Raymo, F. M.; Houk, K. N.; Stoddart, J. F. J. Am. Chem. Soc. 1998, 120, 9318. doi:10.1021/ja9806229

8. Houk, K. N.; Nakamura, K.; Sheu, C.; Keating, A. E. Science 1996, 273, 627. doi:10.1126/science.273.5275.627

9. Maslak, V.; Yan, Z.; Xia, S.; Gallucci, J.; Hadad, C. M.; Badjić, J. D. J. Am. Chem. Soc. 2006, 128, 5887. doi:10.1021/ja060534।

10. Wang, B.-Y.; Bao, X.; Stojanovic, S.; Hadad, C. M.; Badjić, J. D. Org. Lett. 2008, 10, 5361. doi:10.1021/ol802199t

11. Wang, B.-Y.; Bao, X.; Yan, Z.; Maslak, V.; Hadad, C. M.; Badjić, J. D. J. Am. Chem. Soc. 2008, 130, 15127. doi:10.1021/ja8041977

12. Wang, B.-Y.; Rieth, S.; Badjić, J. D. J. Am. Chem. Soc. 2009, 131, 7250. doi:10.1021/ja9023868

13. Rieth, S.; Badjić, J. D. Chem.-Eur. J. 2011, 17, 2562. doi:10.1002/chem.201003138

14. Rieth, S.; Bao, X.; Wang, B.-Y.; Hadad, C. M.; Badjić, J. D. J. Am. Chem. Soc. 2010, 132, 773. doi:10.1021/ja908436c

15. Helgeson, R. C.; Hayden, A. E.; Houk, K. N. J. Org. Chem. 2010, 75, 570. doi:10.1021/jo9012496

16. Sheu, C.; Houk, K. N. J. Am. Chem. Soc. 1996, 118, 8056. doi:10.1021/ja9535423

17. Wang, X.; Houk, K. N. Org. Lett. 1999, 1, 591. doi:10.1021/ol9900820

18. Hooley, R. J.; Van Anda, H. J.; Rebek, J., Jr. J. Am. Chem. Soc. 2006, 128, 3894. doi:10.1021/ja058727g

19. Zhou, H.-X.; McCammon, J. A. Trends Biochem. Sci. 2010, 35, 179. doi:10.1016/j.tibs.2009.10.007

20. Kamieth, M.; Klärner, F.-G.; Diederich, F. Angew. Chem., Int. Ed. 1998, $37,3303$.

doi:10.1002/(SICI)1521-3773(19981217)37:23<3303::AID-ANIE3303>3 .0.CO;2-T

21. Dill, K. A. J. Biol. Chem. 1997, 272, 701. doi:10.1074/jbc.272.2.701

22. Craig, S. L.; Lin, S.; Chen, J.; Rebek, J., Jr. J. Am. Chem. Soc. 2002 , 124, 8780. doi:10.1021/ja025672z

23. Wilcox, C. S. In Frontiers in supramolecular organic chemistry and photochemistry; Schneider, H.-J; Dürr, H., Eds.; VCH: Weinheim, Germany, 1991; pp 123 ff.
24. Mecozzi, S.; Rebek, J., Jr. Chem.-Eur. J. 1998, 4, 1016. doi:10.1002/(SICI)1521-3765(19980615)4:6<1016::AID-CHEM1016>3. $0 . \mathrm{CO} ; 2-\mathrm{B}$

25. Perrin, C. L.; Dwyer, T. J. Chem. Rev. 1990, 90, 935. doi:10.1021/cr00104a002

26. Lian, L. Y. In NMR of macromolecules : a practical approach; Roberts, G. C. K., Ed.; IRL Press: Oxford, 1993; pp 153 ff.

27. Led, J. J.; Gesmar, H.; Abildgaard, F. Methods Enzymol. 1989, 176, 311. doi:10.1016/0076-6879(89)76017-1

28. Hansen, D. F.; Led, J. J. J. Magn. Reson. 2003, 163, 215. doi:10.1016/S1090-7807(03)00062-4

29. Duan, Y.; Wu, C.; Chowdhury, S.; Lee, M. C.; Xiong, G.; Zhang, W.; Yang, R.; Cieplak, P.; Luo, R.; Lee, T.; Caldwell, J.; Wang, J.; Kollman, P. J. Comput. Chem. 2003, 24, 1999. doi:10.1002/jcc.10349

30. Wang, J.; Wolf, R. M.; Caldwell, J. W.; Kollman, P. A.; Case, D. A. J. Comput. Chem. 2004, 25, 1157. doi:10.1002/jcc.20035

31. Isralewitz, B.; Gao, M.; Schulten, K. Curr. Opin. Struct. Biol. 2001, 11, 224. doi:10.1016/S0959-440X(00)00194-9

32. Sotomayor, M.; Schulten, K. Science 2007, 316, 1144 doi:10.1126/science.1137591

33. Sandström, J. Dynamic NMR Spectroscopy; Academic Press: London, 1982.

34. Bao, X.; Rieth, S.; Stojanović, S.; Hadad, C. M.; Badjić, J. D. Angew. Chem., Int. Ed. 2010, 49, 4816. doi:10.1002/anie.201000656

35. Christensen, T.; Gooden, D. M.; Kung, J. E.; Toone, E. J. J. Am. Chem. Soc. 2003, 125, 7357. doi:10.1021/ja021240c

36. Northrop, B. H.; Braunschweig, A. B.; Mendes, P. M.; Dichtel, R. W.; Stoddart, J. F. Molecular Machines. In Handbook of Nanoscience, Engineering, and Technology, 2nd ed.; Goddard, W. A.;

Brenner, D. W.; Lyshevski, S. E.; lafrate, G. J., Eds.; CRC Press: Boca Raton, 2007; 11-1-11-50.

37. Saha, S.; Stoddart, J. F. Molecular Motors and Muscles. In Functional Organic Materials; Müller, T. J. J.; Bunz, U. H. F., Eds.; Wiley-VCH: Weinheim, Germany, 2007; pp 295 ff.

\section{License and Terms}

This is an Open Access article under the terms of the Creative Commons Attribution License (http://creativecommons.org/licenses/by/2.0), which permits unrestricted use, distribution, and reproduction in any medium, provided the original work is properly cited.

The license is subject to the Beilstein Journal of Organic Chemistry terms and conditions:

(http://www.beilstein-journals.org/bjoc)

The definitive version of this article is the electronic one which can be found at: doi:10.3762/bjoc.8.9 